\title{
Presidential Spotlight: Dialoguing the Possible- Creating a Public Record of CSCA Challenges, Lessons Learned, and Envisioning the Future
}

\author{
M. Chad McBride $(\mathbb{0}$ \\ Chad C. Edwards (1)
}

When I was asked to write a Presidential Spotlight, I could not imagine doing it without Chad Edwards, who served as Executive Director in my First Vice Presidential planning year in 2019 in Omaha and during my Presidential year that was the conference cancelled due to the COVID-19 pandemic. I texted with Chad on nearly a daily basis across these two years because of the opportunities and serious challenges we faced in our roles serving CSCA. There was no way I could reflect on and write about this time in our organization's and my personal history without Chad by my side again, this time as a co-author. Additionally, through these two years and endless conversations, we have become bonded for life, as life-long friends and chosen brothers forged through our experiences together resulting in a fierce loyalty and deep love. So, through this reflection, "I" (Chad McBride) will sometimes speak in first, singular person and refer to Chad (Edwards), and sometimes "we" will speak in first person together.

When Chad took on his role of Executive Director, a former CSCA President suggested he read Miller's (2007) article about the financial challenges CSCA faced in the 1980s. We had no way of knowing we would face our own challenges, and that article served as guidance, inspiration, and hope as we navigated current issues. In the spirit of that article, we write this essay to document the more recent history of CSCA should it be useful for future leadership. In what follows, I describe my intentions when choosing the theme of Dialogue for my planning year and focus as a President, we write about the challenges and state of CSCA, and finally we reflect on some lessons learned and envision the future.

\section{Planning for "Dialogue"}

When I was asked if I would consider being on the ballot, I spent some time reflecting. Along with my husband Allen, I was an unexpected new parent through a chance phone call asking if we would be 
interested in adoption. Because I never thought I would have the opportunity to be a dad, I hesitated to take on this service out of fear that I would miss any second with my young son. But then I thought back to my years of experiences with CSCA, including my first conference in 2001 as a first-year PhD student at the University of Nebraska-Lincoln and rooming with my fellow graduate students, Karla Bergen, Leah Bryant, and Shawn Wahl. Also, at that conference, I met Chad Edwards at the Graduate Student Caucus business meeting. From that moment on, I attended CSCA nearly every year, and it became my regional association home, not just because I also happened to land a dream job at Creighton University in the Central region, but because of the influential personal and professional relationships I formed through it. Additionally, my scholarship and teaching were shaped by the conversations I had at CSCA, like with Allison Thorson about a new research idea on work spouses. So when I was asked to be on the ballot, this history pushed me to agree to the request. Through my $\mathrm{PhD}$ advisor, Dawn O. Braithwaite, I learned the importance of giving back to the organizations that are so important to our discipline.

Immediately, I knew what I wanted my planning theme to be. As a student, teacher, and scholar of interpersonal and family communication, Martin Buber (1985) and his writings on dialogue were foundational to my views on teaching and writing about relationships and also served as my personal ethic of interacting with people in the world. Shaped by John Stewart's (2012) Bridges Not Walls, I talked with students about maximizing the presence of the personal and, when possible, to be vulnerable in our communication with others, to open ourselves up as individuals, and to appreciate and learn from others' unique personhood and experiences. I envisioned that possibly this quality of communication could break down some of our disciplinary silos related to content areas or methodological preferences when working with interest group planners to put together a program that hopefully encouraged dialogue around important ideas across the membership.

As President, it was my intention to build on Amy Aldridge Sanford's planning theme of Difference to use dialogue as a model for how to have difficult conversations about critical topics in our discipline and world, particularly as it related to issues of diversity and inclusivity in our own organization. Others had started these conversations and put them into action by creating the new caucus on Ethnicity, Race, International, and Class concerns (ERIC), brainstorming what would become the Calloway-Thomas speaker series, and filming of a video for the inclusive conference spaces project. In the summer of 2019, the controversy surrounding the National Communication Association's Distinguished Scholars erupted. With much help from Vice President Al González and others on the Executive Committee (EC), Chad and I drafted a statement of solidarity with those expressing concerns. We vowed to reflectively examine CSCA's policies and practices to do better as an organization. I will never forget each EC member jumping into this crucial conversation in the middle of their summer activities to brainstorm, vote, and sign the statement over a weekend. From that moment, the (desired) focus of my Presidential year became clear. While we were amid bylaw revisions already, I committed with the EC to further revise our bylaws and examine practices and to create a special ad hoc committee to do the hard work of brainstorming ways to put abstract ideas into action that would meaningfully change CSCA to make it a more inclusive space in our discipline. I envisioned the principles of dialogue would be instrumental in this process.

Little did I know when I proposed this theme in 2016 that our nation's Presidential election would ignite deep divides in our culture. And as we write this, our country is in a pandemic that is highlighting some cultural divides in our health-care system and in the debate on how to handle the current health crisis. And the latest murders of Black men and women have re-ignited protests and significant movement on discussions of systemic racism in our country (and world). I contend that Buber's (1985) notions 
of dialogue could be crucial in moving us through these times and for the collective us to finally really listen to and appreciate the experiences of our black and brown sisters and brothers to take collective action to be anti-racist and hopefully finally change the structures of oppression that have infiltrated all of our systems in our country and our discipline. And with a charge written with Al González, just this year, we finally have the CSCA ad hoc committee (chaired by Ahmet Atay) to tackle these same issues for our organization. I am thankful for their leadership in moving this initiative forward.

\section{Facing Realities in CSCA}

As is often the case, I am idealistic in my goals and plans. While I had lofty hopes with my vision of dialogue (and still do for our organization, discipline, and country moving forward), the realities of a leadership role and the unique demands on our time working together soon took priority. Previous leadership made the good decision that CSCA needed to move technologically into the future and have an online submission and review system. However, we did not appreciate what the realities of tackling this technological transition meant. While the organization that we worked with for the submission system had worked with NCA and other academic conferences, the database and system had to be built from the ground up for CSCA. This development included making a wide range of decisions from the types of submissions accepted to the required fields for each and the access rights for leadership, planners, and reviewers. The system would allow us to streamline messages for receipt, acceptance, and rejection of submissions, but all of these messages had to be created. And because the system was built uniquely for CSCA, it required rounds of testing and troubleshooting and almost weekly Zoom meetings with developers (before Zoom meetings were as ubiquitous as they are now for us all in a pandemic). During this time, our practice of daily texting and phone calls started, and our personal relationship developed.

Throughout the fall, the group planners exercised patience as we rolled out the new system for members to submit and worked out the bugs in real-time. Because the system was unique for CSCA, there was no user documentation or training materials for how to use it for submitters, planners, or reviewers. They were patient as we wrote these user manuals for each step of the process, often days before they were implemented. They fielded member questions and problems and reported them so we could find fixes. All of their names are etched in my brain from the countless emails exchanged and in gratitude for the work they did to make the system go its first year. And because my time was spent on logistics, any implementation of my vision for dialogue for the conference were thanks to them.

Once the acceptance decisions were made and panels built by the planners, our focus moved to how exactly to build a program in this system. Chad E. flew to Omaha so that we could work in real-time in the same room. Deb Ford, also at Creighton, joined us in my department's conference room where we taught ourselves how to do this step. The next day, I texted Chad E. at 5:00 a.m. to report my son was sick and that I would need to take the afternoon off to care for him. Without missing a beat, he said family was the most important, and if I was up, did I want to start now. So, at 5:30 a.m., with coffee and Mountain Dew in hand, we watched YouTube videos on how to mail merge databases into a Word document that would begin to look like a printed program. I will never forget his support and adaptability for my family and me.

When the conference happened, we breathed a sigh of relief. We thought the biggest challenges of our tenure at CSCA were behind us. We were sad that our excuse for daily texts was seemingly over. However, the next summer and fall, we realized the extent of the dire situation the organization was in related to our nonprofit and organizational status, which would have to take priority over any other plans or hopes 
we had. In summer and early fall 2019, we began to realize the length of time that had passed since tax paperwork had been filed and the extent of the ramifications resulting from years of delinquency, including the loss of our organizational status. We had been communicating updates to Jeff Child, Chair of the Finance Committee, as these details emerged. In October, we alerted the entire EC to get approval to hire additional tax and legal professionals to advise us on how to proceed to get CSCA back in good standing.

At the same time, we had a group of members who had proposed a model for faculty learning communities to tackle inclusivity issues at CSCA that needed considerable funding. Because we were not sure how long it would take to tackle the immediate tax and organization status issues, how much it might cost, or what work, if anything, we could legally do without a recognized organizational status, we had to delay discussion of their proposal. Two lead authors of the proposal requested to meet with executives during our meeting at NCA in Baltimore, but we knew the meeting would be taken up with the immediate, pressing concerns. The proposal authors were understandably concerned about the perceived lack of attention to their proposal. Because of our commitment to and plans with these issues, it was hard not be able to provide context and details beyond stating there were "immediate and pressing issues that had to take priority that we were not able to discuss widely yet."

As expected, the bulk of the time at our NCA meeting was spent on the tax and organizational status issues. The EC was supportive and carefully deliberative. We realized other issues, like our inability to fundraise or approve any other major expenses (outside of typical conference budgets) for any initiative. The EC reinforced the importance of communicating to the members about our status and how we planned to move forward as an organization. They also made and approved a motion regarding the proposal related to inclusivity and diversity in hopes that it would formally communicate a commitment to these issues.

After the executive meeting, a long-standing member of CSCA recommended that we consider an ad hoc committee of Past-Presidents and experts in these issues. We discussed the idea, and we wanted an unbiased third party to review the situation, provide us advice, and offer suggestions to hopefully avoid these problems in the future. Christie Beck, Deanna Sellnow, and Don Ritzenhein graciously agreed to serve in this capacity and provided feedback on the statement we made to the full membership (The full statement from November 19, 2019, can be found here linked in the appendix along with the final report of the ad hoc committee. Other documents of record can be found in meeting minutes on the CSCA website).

We had not run the idea for the committee by the full executive board since it is in the purview for the President to create ad hoc committees and, to be honest, we did not brainstorm this idea until after the NCA meeting. Some EC and general CSCA members understandably expressed concern about our creation of this committee, particularly because we had committed to moving the organization forward rather than looking back. We feel strongly that the ad hoc committee was an essential step for learning from our mistakes and creating new practices of checks and balance for the organization.

Once we crafted the notice to send to members regarding the tax and regulatory issues of CSCA, several EC members reviewed and helped edit drafts. It was during this time we informed the last 5 past-presidents and most of those Executive Committees that their names would be listed on forms that had to be given to the IRS for delinquent filings. Many had questions and expressed support for things we might need from them. Our goal was to always be transparent without causing unnecessary 
turmoil. Organization leaders have the responsibility to report to members timely information about the organization. We wanted to make sure that CSCA members knew the state of the organization. In early 2020, we were able to submit all the tax filings from the previous executive director. We were also given status in West Virginia and then later in Ohio. As of July 1,2020, we are still working with the IRS on the last few steps but these should be finished by the fall of 2020 .

Around February 15th 2020, Chad and I talked about COVID-19 for the first time. At this point, the virus was starting to take hold in Seattle. On March 2th, we talked about the pandemic in relation to the upcoming CSCA conference. On March 9th, the EC voted to cancel CSCA. Though it was a difficult decision, we knew it was the right thing to do. Al González succinctly said in a group email that we were elected to make these decisions. He was right. When we decided, we did not know if the hotel contract would be in full effect. The Executive Committee made the only choice we could. Could we stand losing one member to the virus because we had a conference? The easy answer was no.

I sent out the email that CSCA 2020 would not happen on March 10th. After we made the choice to cancel CSCA, the EC gave full authority and funding to Chad Edwards to use our legal team to dispute the hotel contract. While I cannot be specific here, just know that this was not an easy task. Chad's strategy with the legal team was both interesting and courageous. Within 24 hours, the hotel had backed down and was even refunding CSCA deposits. Many other organizations that had to cancel due to the pandemic did not get these favorable terms. First Vice-President Al González was an amazing leader during this time. After all of his work to build an amazing program, he was quick and responsive at reversing course. CSCA owes Al so much gratitude for his leadership during COVID-19.

On a personal note, in December of 2019, I started seeing doctors for some concerning symptoms and was officially diagnosed with ALS in January 2020. I share this personal information as yet another example of how people in CSCA step up when needed. When faced with this personal health crisis, Chad and Jeff Child were some of the first people I told, even before I had a definitive diagnosis. They both immediately stepped in to respond to emails and take care of issues without me asking. I will never forget one email from someone pushing us for a quick response where Chad answered the query and kindly reminded the person that CSCA was made up of volunteers with our own family and personal issues. I knew they had my back when I needed to step away. In early February, I informed the rest of the EC about my diagnosis. I was flooded with emails of condolence/concern and offers to help. Specifically, Al González took the lead for drafting the charge for the ad hoc committee on diversity and inclusion. Anna Wright and Amy Aldridge Sanford offered help in finalizing the planning for the President's Undergraduate Honors Research Conference, and Tiffany Wang carefully proofed and edited the program for the UHRC (as she finalized the entire program so that Chad could focus on our legal issues). Hence, the support of CSCA members during my personal health crisis goes well-above what was necessary and relates to some of our lessons learned outlined below.

\section{Lessons Learned and Envisioning the Future}

We share this narrative to document the realities of CSCA over the past 2 years for historical record not only to record the work done by so many and to publicly thank them, but also to continue our efforts of transparency so future leaders of CSCA can learn from our experiences to continue to make CSCA even stronger. We have reflected ourselves to offer some lessons learned. 
First, the importance of clear communication and appropriate organizational transparency were reinforced. Program planners were able to help facilitate and implement the usage of the new online submission system because of clear communication. And hopefully the membership benefitted from our attempts at transparency throughout the legal and tax issues and response to the COVID-19 pandemic. Our goal was to communicate these issues in a way to garner membership trust in the organization.

Second, we learned the importance of deliberative and swift action. From the legal issues to the COVID19 response, the Executive Committee was flexible with their time to make quick decisions while also being careful to make sound choices that aligned with our mission. They did due diligence and also empowered people to take action.

Third, we learned that you cannot please everyone. We had to think about and do what is best for CSCA and be accountable to our members. We received feedback that was not always positive as it related to our handling of legal issues and the cancellation of the conference. However, we are confident we did the best we could for the future of CSCA.

Fourth, we learned the importance of leaders to have plans but also to pivot to address other issues as they arise. We could not have planned for the challenges that arose.

Finally, we learned the importance of relationships. As someone who has dedicated my professional life's work to the study and teaching of communication in relationships, it became clear how important relationships are in navigating organizational crises. CSCA was built from relationships, and our members often report that these relationships are what brings them back and makes our organization strong. From our experience this year, our strong relationships cultivated with the Executive Committee and previous leadership were instrumental in tackling the issues over the last 2 years. We hope this essay is clear that it was an entire team of people stepping in for advice and action that has solidified a future for CSCA when there were times when we were seriously concerned about the organization surviving. Neither of us could have navigated these years without this help and without the strong relationships created with others (including our home departments and personal families) and each other.

We are confident that the future of CSCA is bright. This does not mean it will be without challenges. The COVID-19 pandemic is not going away and leadership is already having discussions about the 2021 conference should we still not be able to safely gather together as a big group. Additionally, to make meaningful, substantive, and systemic changes to CSCA to truly embody our goals of diversity and inclusion will require moments of discomfort, vulnerability, and reflexivity. We are confident that through dialogue the future leadership can build a stronger future that envisions what is possible as a leading organization in our discipline.

\section{References}

Buber, M. (1985). I and Thou (2nd ed.). New York: C. Scribner's Sons.

Miller, L. D. (2007). How the South helped save the North when the lights went out. Southern Communication Journal, 72(1), 87-93. https://doi.org/10.1080/10417940601175063

Stewart, J. (2012). Bridges not walls: A book about interpersonal communication (11th ed.). New York: McGraw Hill. 


\section{APPENDIX Archived Links of the Central States Communication Association}

November 19, 2019, Statement from the President and Executive Director of CSCA:

https://web.archive.org/save/https://www.csca-net.org/aws/CSCA/pt/sd/news_article/265245/_PARENT/ layout_details/false

Final report of the ad hoc committee:

https://web.archive.org/web/20200701164749/https://www.csca-net.org/aws/CSCA/asset_manager/get_ file/463345?ver=119 
